\title{
Spectrophotometric Determination of Fluconazole, Voriconazole and Butoconazole nitrate by Ion-Pair Formation with Rose Bengal Reagent
}

\author{
Mohamed A. Zayed ${ }^{1 *}$, Manal A. El-Shal ${ }^{2}$ and Marwa A. Abdallh ${ }^{2}$ \\ ${ }^{1}$ Chemistry Department, Faculty of Science, Cairo University, 12613 Giza, Egypt. \\ ${ }^{2}$ National Organization for Drug Control and Research (NODCAR), Giza, Egypt.
}

\begin{abstract}
T HE REACTIONS of Rose bengal reagent (Rbeng) with three antifungal drugs Fluconazole (FLZ), Voriconazole (VRZ) and Butoconazole nitrate (BTZ) had been studied for the development of simple, rapid, sensitive spectrophotometric methods for micro-determining of these drugs in pure and in their dosage forms. This method is based on the formation of ionpairs between the drugs and Rbeng reagent. The spectra of the formed ion pairs were measured at $\mathrm{pH}=6.5$ for $\mathrm{FLZ}$ and $\mathrm{pH}=6$ for $\mathrm{VRZ}$ at $575 \mathrm{~nm}$. The spectra of the formed ion pair for BTZ was measured at $\mathrm{pH}=4$ and at $580 \mathrm{~nm}$. All solutions spectra are measured at selected optimum temperature $20-30{ }^{\circ} \mathrm{C}$. Beer's law was valid in the concentration ranges $30.63-76.57,34.93-$ 97.81 and $14.2-45.1 \mu \mathrm{g} \mathrm{ml}^{-1}$ with recovery of $(98.00-101.9,97.92-102.2$, and $98.20-101.3$ $\%$ for FLZ, VRZ and BTZ, respectively. The values SD $=0.1210-0.4148,0.4365-1.018$ and $0.0748-0.4362$, RSD $=0.1790-1.152,0.5248-1.648$ and $0.3314-1.011 \%$, the Sandell sensitivity $(\mathrm{S})=0.063,0.076,0.017 \mu \mathrm{g} \mathrm{cm}^{-2}, \mathrm{LOQ}=8,12.96,13.27 \mu \mathrm{g} \mathrm{m} \mathrm{l}^{-1}$ and $\mathrm{LOD}=2.6$, 4.4, $4.3 \mu \mathrm{g} \mathrm{ml}^{-1}$ were calculated for FLZ, VRZ and BTZ, respectively. The results obtained revealed accuracy, precision and sensitivity of the suggested procedures. These methods were applied for analysis of these drugs in their pharmaceutical formulations. The results obtained were found to be in good agreement with those given by official methods, as evaluated by Fand $\mathrm{t}$ - tests.
\end{abstract}

Keywords: Fluconazole, Voriconazole, Butoconazole nitrate, Rose Bengal, Ion pair formation, Microdetermination, Spectrophotometry.

\section{Introduction}

For many years, the treatment of most invasive fungal infections was essentially limited to amphotericin B (AmB) with or without 5-flucytosine (5-FC). As the use of $\mathrm{AmB}$ was associated with infusion-related side effects and dose-limiting nephrotoxicity, the continuous search for newer, less toxic antifungals led to the discovery of the azoles. The therapeutic options did not expand until the late 1980s, when fluconazole and itraconazole were introduced. Triggered by the increasing number of neutropenia patients and patients with acquired immunodeficiency syndromes (AIDS), the past decade, however, has seen a major expansion in antifungal drug research. These efforts have resulted in the discovery or design of several new antifungal compounds that are currently at various stages of clinical investigation [1-2]. Azole antifungals are widely used for the treatment of superficial and invasive fungal infection and include the three generations of imidazole- and triazole-containing pharmaceuticals [3]. Azole antifungal agents prevent the synthesis of ergosterol, a major component of fungal plasma membranes, by competitively inhibiting the cytochrome P450-dependent enzyme lanosterol 14 $\alpha$-demethylase (P45014DM, CYP51) [4-7]. Exposure of fungi to an azole causes depletion of ergo-sterol and accumulation of lanosterol and other $14 \alpha$-methylated sterols. This interferes with the "bulk" functions of ergo-sterol in fungal membranes and disrupts both the structure of the membrane and several of its functions such as nutrient transport and chitin synthesis. The net result is the growth inhibition of fungal cells. Ergo-sterol also has a hormone like ("sparking") function in fungal cells, which stimulates growth and proliferation [8-9]. The 
basic nitrogen atoms of the imidazoles (N3) and triazoles (N4) forms a bond with the heme iron of the P45014DM prosthetic group in the position normally occupied by the activated oxygen. The remainder of the azole antifungal forms bonding interacts with the apoprotein in a manner which determines the relative selectivity of the drug for the fungal demethylase versus other CYP450 enzymes [10]. Fluconazole and Voriconazole are triazole antifungals whereas Butoconazole is imidazole antifungal. Fluconazole, [2-(2, 4-difluorophenyl)-1, 3-bis (1H-1, 2, 4-triazol-1-yl) propan-2-ol] (I), is an orally active antifungal agent, which is used in the treatment of superficial and systemic candidiasis and Cryptococci infections in patients with the acquired immunodeficiency syndromes (AIDS) ${ }^{(11)}$. Voriconazole, designated chemically as $(2 R, 3 S)-2-(2,4$-difluorophenyl)3 - ( 5 - fluoro - 4 - pyrimid inyl) - 1 - ( $1 H-1,2$, 4-triazole-1-yl)-2-butanol (II), is currently the drug of choice for the treatment of invasive aspergillosis [12]. Butoconazole nitrate[( \pm -1(4-Chlorophenyl)-2-(2, 6-dichlorophenylthio)- n-butyl imidazole nitrate] (III), an imidazole developed by Syntex research [13, 14], is active as an antifungal agent in vivo and in vitro. It exists as a racemic mixture in which both components are optical isomers and equally active [15-17]. Butoconazole nitrate (BTZ) has been singled out for clinical studies since it is proven to be more effective than either miconazole nitrate or clotrimazole in experimental vaginal candidiasis [18-20]. Due to the vital importance of these azole antifungals several methods have been reported for the determination of them either in pure forms, dosage forms, or biological fluids like chromatography [21-25], spectrophotometric [2631], electrometric [32-33]. Simpler alternative methods that use inexpensive instruments are clearly needed for the determination of these pharmaceutically important antifungal drugs. In the present work, accurate and precise spectrophotometric methods have been developed based on formation of ion pairs between the studied azole antifungals (FLZ, VRZ, and BTZ) and Rose bengal organic reagent. These drugs have the following structural formulae:

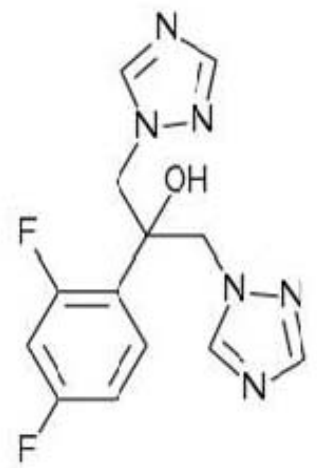

Fluconazole

(I)<smiles>C[C@@H](c1ncncc1F)[C@](O)(Cn1cncn1)c1ccc(F)cc1F</smiles>

Voriconazole

(II)

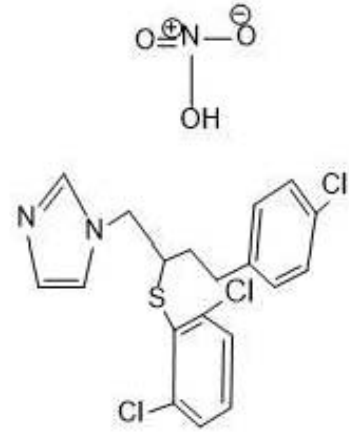

Butoconazole nitrate

(III)

\section{Experimental}

Materials and solutions

All chemicals used were of analytical reagent grade (AR), and of highest purity available. They included FLZ $\left(\right.$ M.wt $\left.=306.271 \mathrm{~g} \mathrm{~mol}^{-1}\right)$ provided by Amoun Pharmaceutical Co, (Egypt), VRZ $\left(\right.$ M.wt $\left.=349.311 \mathrm{~g} \mathrm{~mol}^{-1}\right)$ provided by Mash Pharmaceutical Co, (Egypt), and BTZ nitrate (M.wt $=474.79 \mathrm{~g} \mathrm{~mol}^{-1}$ ) provided by Sabaa Pharmaceutical Co, (Egypt). Rbeng disodium salt reagent was supplied from BDH Chemicals

Ltd, Poole, England. Absolute ethanol (99.8\%, Sigma Aldrich, Germany), phosphoric acid ( 88 $\%, \mathrm{BDH}$, England), acetic acid (El Salam for chemical industries, Egypt), boric acid (ADWIC), Analar sodium hydroxide (Merck, Germany) and distilled water, obtained from all glass equipment, were used.

Stock solution of $1 \times 10^{-3} \mathrm{M}$ Rbeng disodium salt $\left(\right.$ M.wt $\left.=1017.64 \mathrm{~g} \mathrm{~mol}^{-1}\right)$, was prepared by dissolving the accurately weighed amount in the appropriate volume of distilled water and the 
volume completed to $250 \mathrm{~mL}$ volumetric flask. Fresh stock solutions of $1 \times 10^{-3} \mathrm{M}$ standard drugs FLZ, VLZ and BTZ respectively were prepared by dissolving the accurately weighed amount of the pure drug 0.0307, 0.0349 and $0.0475 \mathrm{~g}$ respectively in absolute ethanol and the volume completed in $100 \mathrm{~mL}$ volumetric flask. Dilute solutions were prepared by accurate dilution from the stock solutions to get the desired concentrations. Series of universal buffer solutions covering the range of $\mathrm{pH}$ values from 2.00 to 11.05 were prepared as recommended by Britton and Robinson [34]. A mixture of $0.04 \mathrm{M}$ phosphoric, acetic and boric acids was titrated with $1 \mathrm{~N} \mathrm{NaOH}$ to adjust the desired $\mathrm{pH}$ into the required value in $100 \mathrm{ml}$ of the acid mixture using $\mathrm{pH}-$ meter. The stoichiometric ratio between drugs and reagent in the ion-pair was determined by the molar ratio method (MRM). In this method to constant reagent concentration of Rbeng, variable concentrations of FLZ, VRZ and BTZ were added. All solutions must be protected from light by keeping them in dark coloured quick fit bottles during the whole work. Diflucan capsules were obtained from Pfizer Egypt S.A.E Pharmaceutical Company, Cairo, A.R.E under Authority of Pfizer INC., USA Labelled to contain $(50 \mathrm{mg}$ FLZ capsule $\left.{ }^{-1}\right)$. Vfend tablet were obtained from Pfizer Egypt S.A.E Pharmaceutical Company, Cairo, A.R.E under Authority of Pfizer INC., USA labelled to contain (50 mg VRZ tablet ${ }^{-1}$ ). Butoconazole 2\% cream were obtained from Sabaa international company for pharmaceuticals and chemical industries S.A.E., Egypt labelled to contain (20 mg BTZ nitrate $1 \mathrm{gm}^{-1}$ ).

\section{Instruments and apparatus}

The spectrophotometric measurements in solutions were carried out using Optizen recording spectrophotometer, UV-Vis range from 150-1100 nm model 5u470\pop 127022-00 and quartz cell of $1 \mathrm{~cm}$ optical length was used, Micropipette, Accupipette USA $(100-1000 \mu \mathrm{L})$, was used to measure the very small volumes, whereas glass pipettes $(2,5 \mathrm{~mL})$ were used to measure the large volumes. Weights measurement was performed by using Sensitive analytical balance of $0.0001 \mathrm{~g}$, RADWAG model As-220 \c $\backslash 1$ (Poland). Stirring and heating were performed by using magnetic stirrer theromostated hot plate (VELP-Europe). The $\mathrm{pH}$ measurements were performed by HANNA pH-meter model pHS-3CW.

\section{Procedures}

Determination of FLZ, VRZ and BTZ using Rbeng reagent

\section{a. General procedure}

The calibration curves of FLZ, VRZ, and BTZ drugs, with Rbeng reagent were constructed by preparing series of solutions of variable concentration of the drugs in which the concentration of Rbeng was kept constant $2.5 \times 10^{-3} \mathrm{M}, 3 \times 10^{-3} \mathrm{M}$ and $2 \times 10^{-3} \mathrm{M}$ Rbeng for FLZ, VRZ and BTZ respectively and the mixture adjusted to the suitable $\mathrm{pH}$ value using buffer solution and the volume completed to with distilled water in $10 \mathrm{ml}$ measuring flask. The absorbance values of reaction products were measured at $575 \mathrm{~nm}$ for FLZ and VRZ and at 580 $\mathrm{nm}$ for BTZ using the reagent as a blank under the proper selected conditions. The calibration curves of the data were plotted. The concentration of the unknown was estimated from the calibration graph or computed from the regression equation.

\section{b. Procedure for pharmacuetical formulation analysis}

The content of ten capsule of Diflucan (Each capsule contains $50 \mathrm{mg}$ of FLZ), were weighed. $70 \mathrm{mg}$ of powder containing $30.6 \mathrm{mg}$ of FLZ dissolved in suitable amount of absolute ethanol, filtered in whatmann No. 1 filter paper and transferred into $100 \mathrm{~mL}$ measuring flask.

For Vfend each ten tablet (50 mg VRZ / tab) of) were weighed and powdered well separately. $107 \mathrm{mg}$ of powder which contains approximately $34.93 \mathrm{mg}$ of VRZ was weighed and dissolved in sufficient amount of absolute ethanol, filtered through whatmann No. 1 filter paper and the filtrate was transferred into $100 \mathrm{ml}$ measuring flask and the volume completed to the mark with ethanol.

For Butoconazole 2\% cream (Each gram contains $20 \mathrm{mg}$ of BTZ $\mathrm{NO}_{3}$ ), $1.187 \mathrm{~g}$ of cream which contains approximately $23.74 \mathrm{mg}$ of BTZ was weighed and dissolved in sufficient amount of methanol HPLC grad and sonicated for 1 hour then centrifuge the solution for $20 \mathrm{~min}$. The resulting solution was filtered through filter paper whatmann No. 1; and transferred into 50 $\mathrm{ml}$ volumetric flask, the volume completed to the mark with methanol HPLC grad.

The spectrophotometric microdetermination of FLZ, VRZ and BTZ in the range 30.63-76.57, 
$34.93-97.81$ and $14.2-45.1 \mu \mathrm{g} \mathrm{ml}{ }^{-1}$ in their formulation solutions had to be done by addition of $2.5 \times 10^{-3} \mathrm{M}, 3 \times 10^{-3} \mathrm{M}$ and $2 \times 10^{-3} \mathrm{M}$ Rbeng for FLZ, VRZ and BTZ respectively and the mixture in each case had been adjusted to the suitable $\mathrm{pH}$ value with buffer and the volume completed with distilled water in $10 \mathrm{ml}$ measuring flask. The measured absorbance value at each concentration was calculated from the standard calibration graph previously prepared under identical conditions.

\section{Results and Discussion}

Optimum reaction conditions for ion pair formation.

Optimum conditions of the methods were carefully studied to achieve complete reaction formation, highest sensitivity, and maximum absorbance.

\section{Effect of time and temperature}

The effect of time on the reaction products of FLZ and VRZ at $575 \mathrm{~nm}$ and BTZ at $580 \mathrm{~nm}$ with reagent Rbeng was studied at time interval of 5 to 60 minutes and the results are shown in Fig 1.

From the obtained results; it is found that the reaction products are stable over one hour and the time has no significant effect on its stability.

The effect of temperature on the drug-reagent ion pairs was studied at temperature range 20$70{ }^{\circ} \mathrm{C}$ by measuring absorbance of the reaction products of FLZ and VRZ at $575 \mathrm{~nm}$ and BTZ at $580 \mathrm{~nm}$ using reagent Rbeng as a blank to select the optimum temperature suitable for each ion- pair and the results obtained are given in Fig 2.

The optimum temperature from the obtained results is found to be $20-30{ }^{\circ} \mathrm{C}$; which gives maximum absorption spectra for all of the given reaction products.

\section{Effects of $p H$ on ion-pair formation.}

The effect of $\mathrm{pH}$ on the drug-reagent ion pairs had been studied at the $\mathrm{pH}$ range 2-11 using Britton -Robinson buffer and the results obtained are shown in Fig 3.

These results reveal that; for FLZ-Rbeng product there is no effect of $\mathrm{pH}$ on its spectrum in the $\mathrm{pH}$ range 3-11 and $\mathrm{pH} 6.5$ is selected to further measurement; while VRZ-Rbeng spectrum $\mathrm{pH}$ ranges $5-8$ is the suitable and $\mathrm{PH}=6$ is selected for its micro determination. For BTZ-Rbeng the $\mathrm{pH}$ range $4-7$ is suitable and $\mathrm{pH} 4$ is selected for further measurements.

Absorption spectra of the obtained ion-pairs

The absorption spectra of the ion-pairs (Fig 4) formed between FLZ, VRZ, or BTZ and reagent Rbeng measured in the wavelength range 400 $-600 \mathrm{~nm}$ against the blank reagent solution are presented in Fig 4.

These results (Fig 4) show that the proper conditions of ion-pair products are $\lambda_{\max } 575 \mathrm{~nm}$ for FLZ-Rbeng at $\mathrm{pH} 6.5$ and at $\mathrm{pH} 6$ for VRZRbeng and at $\mathrm{pH} 4$ for BTZ-Rbeng, at $\lambda_{\max }=580$ $\mathrm{nm}$, at suitable time of 10-20 min and temperature 20-30 ${ }^{\circ} \mathrm{C}$ for all of them.

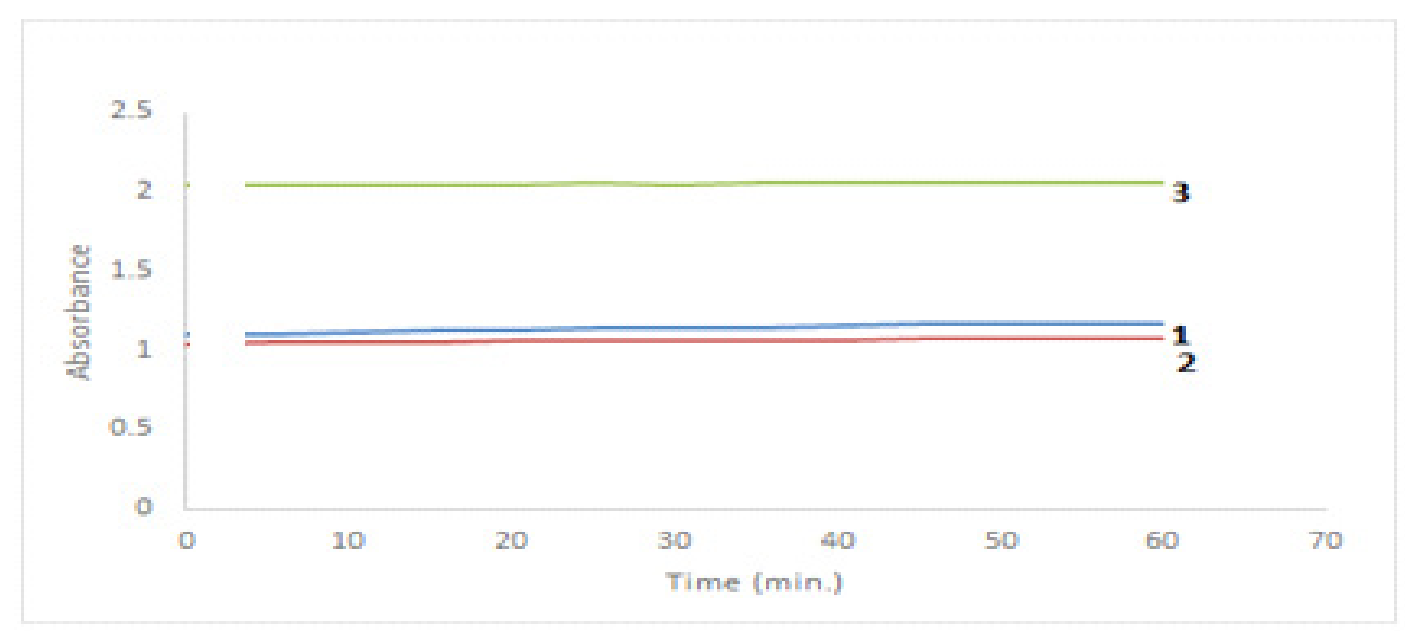

Fig 1. Effect of time on the ion pair reaction products of 1.FLZ-Rbeng, 2.VRZ-Rbeng, at $\lambda_{\max }=575 \mathrm{~nm}$. 3. BTZRbeng at $\lambda_{\text {max }}=580 \mathrm{~nm}$.

Egypt. J. Chem. 60, No. 6 (2017) 

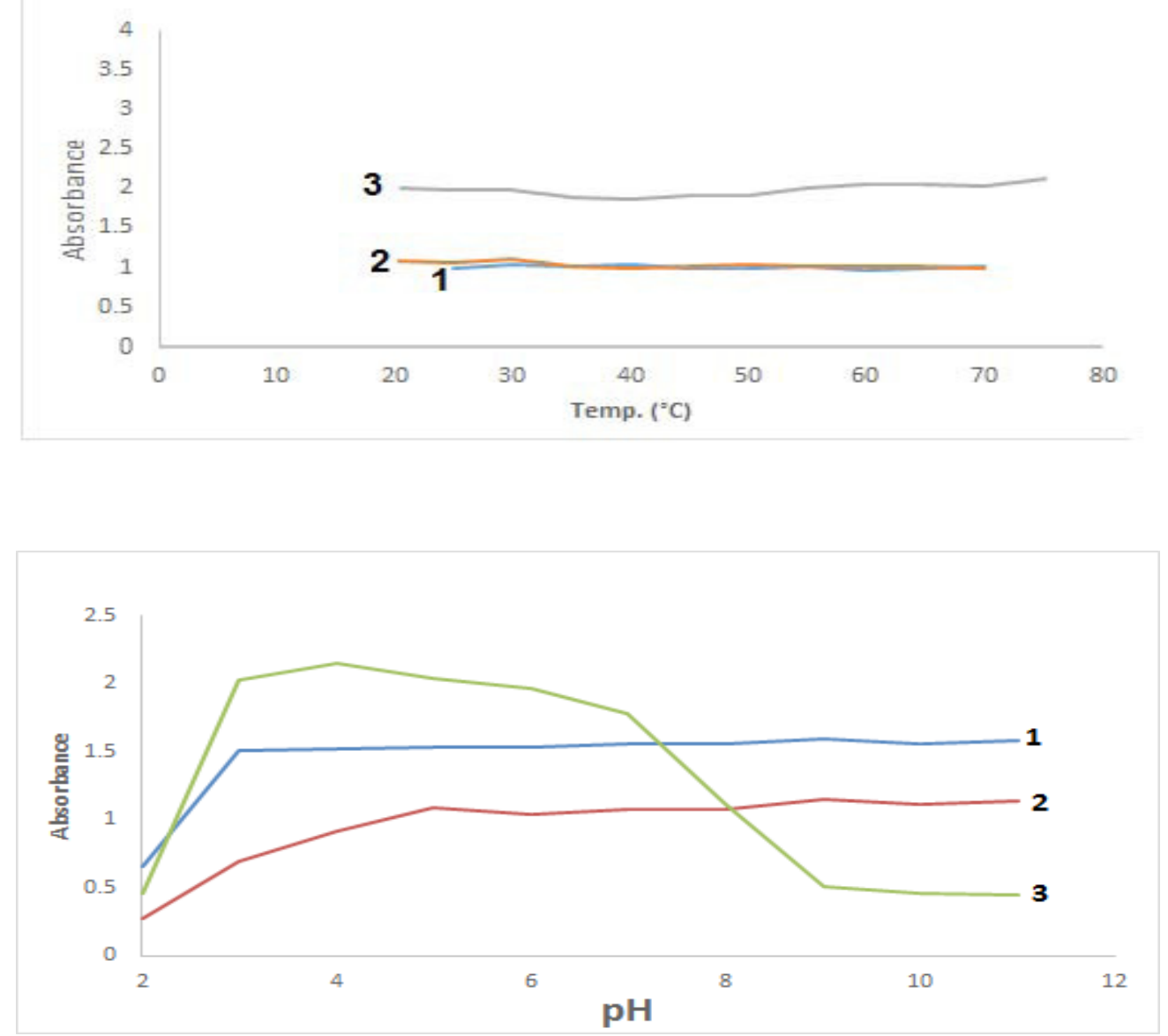

Fig. 3. Effect of $\mathrm{pH}$ on the colour ion pair reaction product of 1.FLZ-Rbeng, 2.VRZ-Rbeng at $\lambda_{\max }=575$ $\mathrm{nm}, 3$. BTZ-Rbeng at $\lambda_{\text {max }}=580 \mathrm{~nm}$.

\section{Stoichiometric relationship}

The stoichiometric ratio between drugs and Rbeng reagent ion-pairs was determined by Continuous variation (CVM) [35] and molar ratio (MRM) [36] methods.

In CVM, series of solutions were prepared by adding different volumes of Rbeng to different volumes of FLZ and VRZ so that the total number of moles was kept constant.

For FLZ $(0.5-5 \mathrm{~mL})$ of $10^{-3} \mathrm{M}$ Rbeng was added to $(5-0.5 \mathrm{~mL})$ of $10^{-3} \mathrm{M}$ standard drug solution at $\mathrm{pH}=6.5$ and at $20-30{ }^{\circ} \mathrm{C}$ and the volume completed to $10 \mathrm{~mL}$ with dist. $\mathrm{H}_{2} \mathrm{O}$. The spectrophotometric measurements of these solutions were recorded at $575 \mathrm{~nm}$, within $20 \mathrm{~min}$. The reagent was used as a blank.
For VRZ $(0.5-6 \mathrm{~mL})$ of $10^{-3} \mathrm{M}$ Rbeng was added to $(6-0.5 \mathrm{~mL})$ of $10^{-3} \mathrm{M}$ standard drug solution at $\mathrm{pH}=6$, temp $20-30{ }^{\circ} \mathrm{C}$ and the volume completed to $10 \mathrm{~mL}$ with dist. $\mathrm{H}_{2} \mathrm{O}$. The spectrophotometric measurements of these solutions were recorded at $575 \mathrm{~nm}$, and within 20 min. The reagent was used as a blank.

In (MRM) the reagent concentration was kept constant, $2.5 \times 10^{-4} \mathrm{M}, 3 \times 10^{-4} \mathrm{M}$ and $2 \times 10^{-4}$ M Rbeng for FLZ, VRZ and BTZ respectively, and to which variable concentrations of the drugs solutions, $0.5-5.8 \times 10^{-4} \mathrm{M}, 1-6 \times 10^{-4} \mathrm{M}$ and $0.3-1.5 \times 10^{-4} \mathrm{M}$ of FLZ, VRZ and BTZ were added respectively. The spectrophotometric measurements of these solutions were recorded at previously mentioned proper conditions using Rbeng as blank at $575 \mathrm{~nm}$ for FLZ and VRZ and at $580 \mathrm{~nm}$ for BTZ at optimum conditions (Fig. $6)$. 

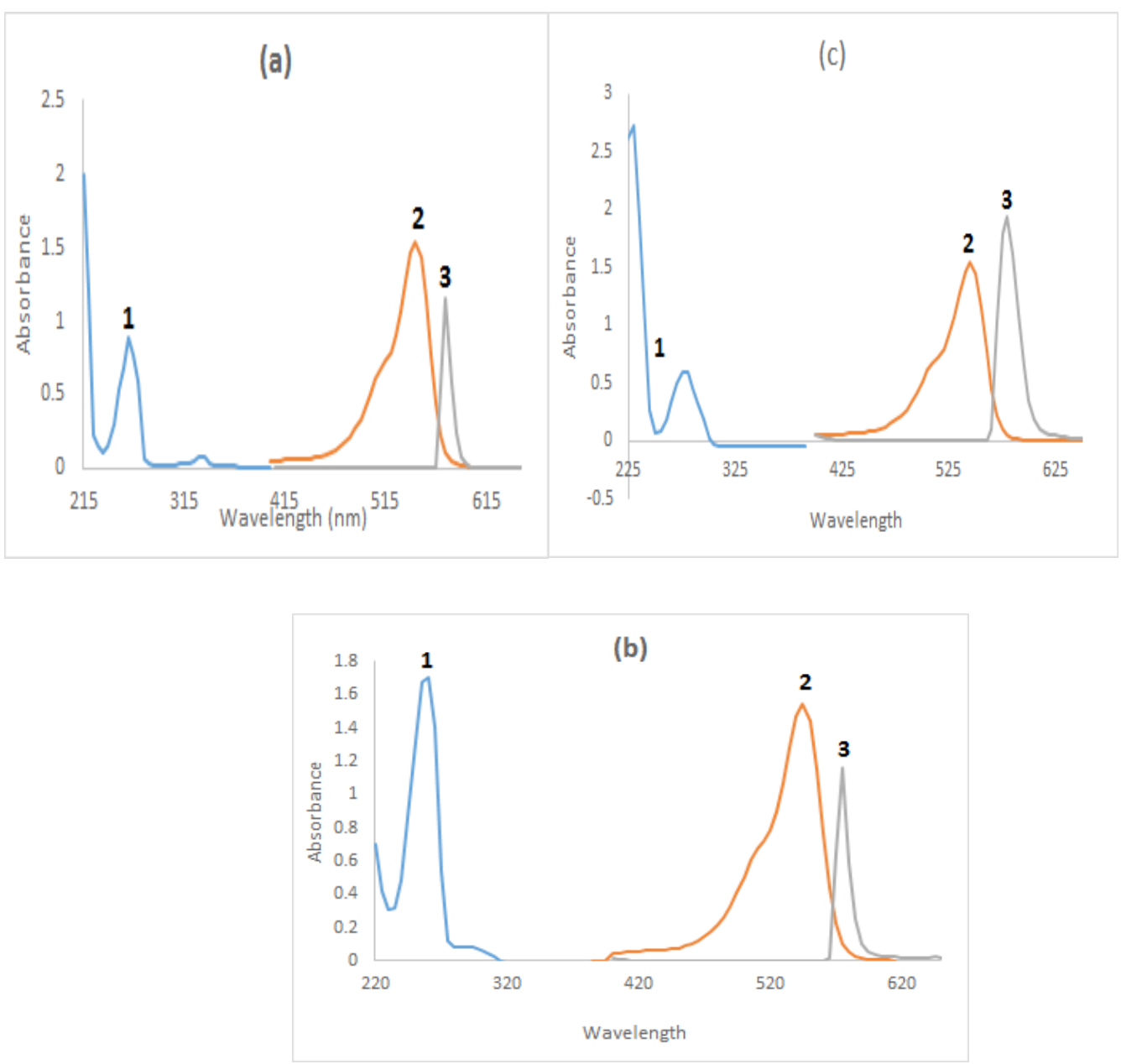

Fig.4. Absorption spectra under selected proper conditions of (a) 1.FLZ, 2. Rbeng, 3.FLZ-Rbeng (b)1. VRZ, 2. Rbeng, 3.VRZ-Rbeng (c)1. BTZ, 2. Rbeng, 3.BTZ -Rbeng.

The results indicate that (drug: reagent; 1:1 and 2:1) for FLZ-Rbeng product, 1:1 ratio for VRZ-Rbeng and 1:2 for BTZ-Rbeng ion-pairs. These ion-pairs are proposed to be formed through the electrostatic attraction between positive protonated drugs at selected acidic $\mathrm{pH}$ $\left(\mathrm{FLZ}^{+}, \mathrm{VRZ}^{+}\right.$, or $\mathrm{BTZ}^{+}$) and negative Rbeng ${ }^{-}$. Scheme 1 represents; as example the ion pair of VRZ-Rbeng.

\section{Validity of Beer's law}

Standard calibration curves for FLZ, VRZ, and BTZ with Rbeng were constructed by plotting absorbance versus drug concentration at optimum described experimental conditions and used for microdetermination of unknown drug concentration and results are presented in Table 1. These results represent different analytical parameters such as slope, intercept, correlation coefficient, Sandell sensitivity, molar absorptivity, standard deviation, and relative standard deviation, limit of quantification and limit of detection.

These results reveal that; Beer's law was valid over the concentration range $30.63-76.57,34.93-$ 97.81 and $14.2-45.1 \mu \mathrm{g} \mathrm{ml}^{-1}$ for FLZ, VRZ, and BTZ using Rbeng respectively. The small value of Sandell sensitivity indicates the high sensitivity of the proposed methods in the determination of the drug under investigation. The limits of detection (LOD) and quantification (LOQ) values confirm the sensitivity of the proposed method. These data also assayed validity of the given methods with respect to linearity, limit of detection, and quantification, repeatability and reproducibility. The linearity of calibration graphs was proved by the high values of the correlation coefficient $\left(\mathrm{r}^{2}\right)$.

The accuracy and precision of the proposed methods were established by measuring the content of FLZ, VRZ and BTZ in pure form at 

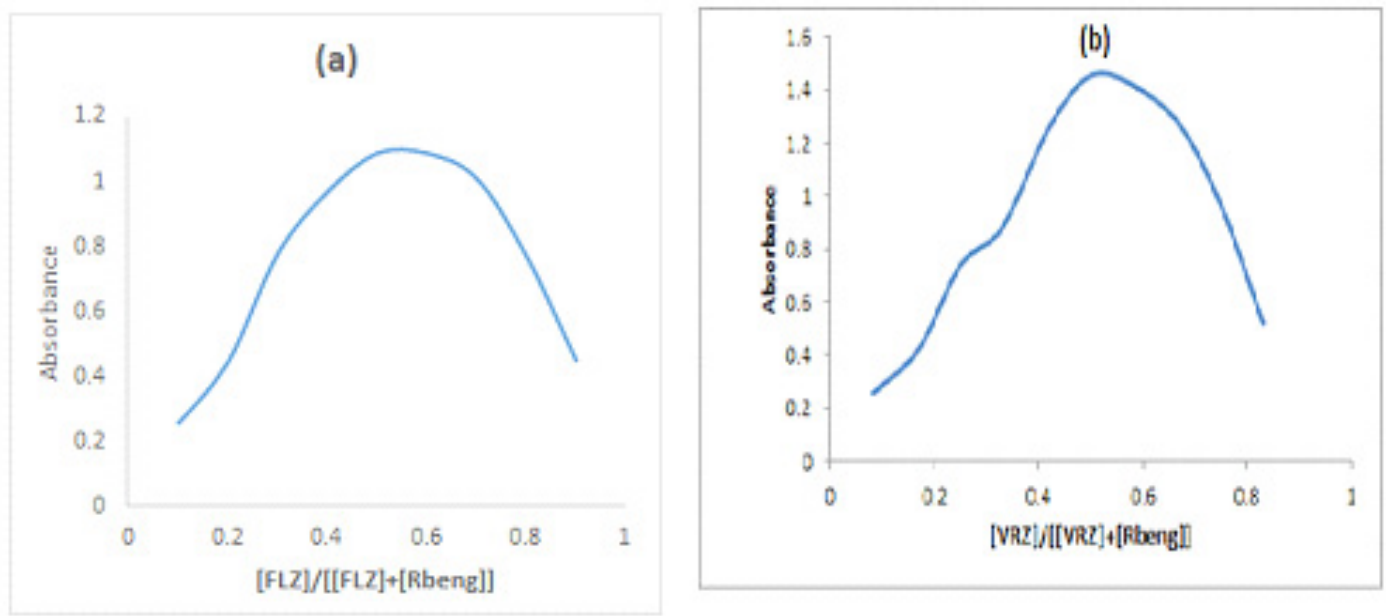

Fig. 5. Stoichiometric ratio of the reaction of (a). FLZ and (b). VRZ with RBeng using CVM at $\left(\lambda_{\max }=575 \mathrm{~nm}\right)$ and at $20-30{ }^{\circ} \mathrm{C}$
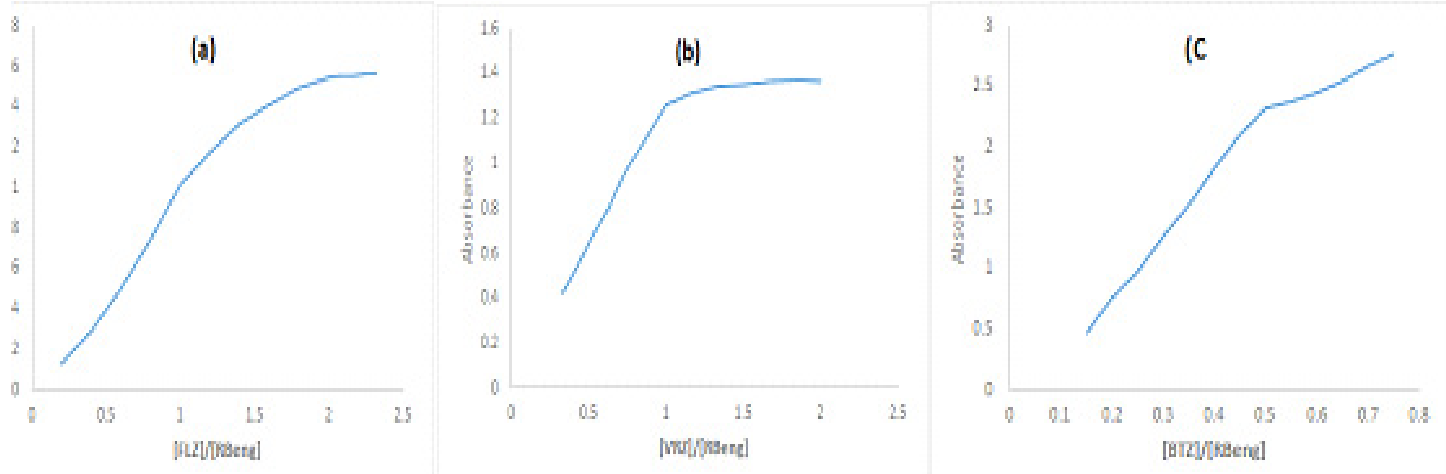

Fig.6. MRM of the reaction of (a) FLZ- Rbeng at $20-30{ }^{\circ} \mathrm{C}, \mathrm{pH}=6.5$ and $\lambda$, $=575 \mathrm{~nm}$. (b) VRZ- Rbeng at $20-30{ }^{\circ} \mathrm{C}$, $\mathrm{pH}=6$ and $\lambda_{\text {max }}=575 \mathrm{~nm}$. (c) BTZ- Rbeng at $20-30^{\circ} \mathrm{C}, \mathrm{pH}=4$ and $\lambda_{\max }=580 \mathrm{~nm}$.

different concentration levels five replicate. The results of standard deviation (SD), relative standard deviation (RSD) and recoveries by the proposed methods are presented in Table 2.

The inter-day precision of the proposed methods is performed by carrying out five replicate experiments at each concentration level within 6 hours (Table 2).

The intra- day precision of the proposed methods is performed by carrying out five replicate experiments at each concentration level within 6 days (Table 3 ).

The results for accuracy and precision show that; the proposed methods have good repeatability and reproducibility. Thus the proposed methods are very effective for the assay of FLZ, VRZ and BTZ drugs.

\section{Analytical applications}

The applicability of the proposed methods for the microdetermination of FLZ, VRZ and BTZ has been tested on commercially available pharmaceutical formulations. The results of the proposed methods are compared with those obtained by the official methods $[26,28,31]$ and the data obtained are given in Table 4.

These results are compared with those obtained from the reference spectrophotometric methods for FLZ and VRZ dosage forms by statistical analysis with respect to the accuracy (by student's t-test) and precision (by F-test) [37] and Butoconazole [20]. No significant differences were found between the calculated and theoretical values of t- and F-tests at $95 \%$ confidence level proving similar accuracy and precision in the determination of the studied drugs by the proposed and reference methods [37, 20]. 


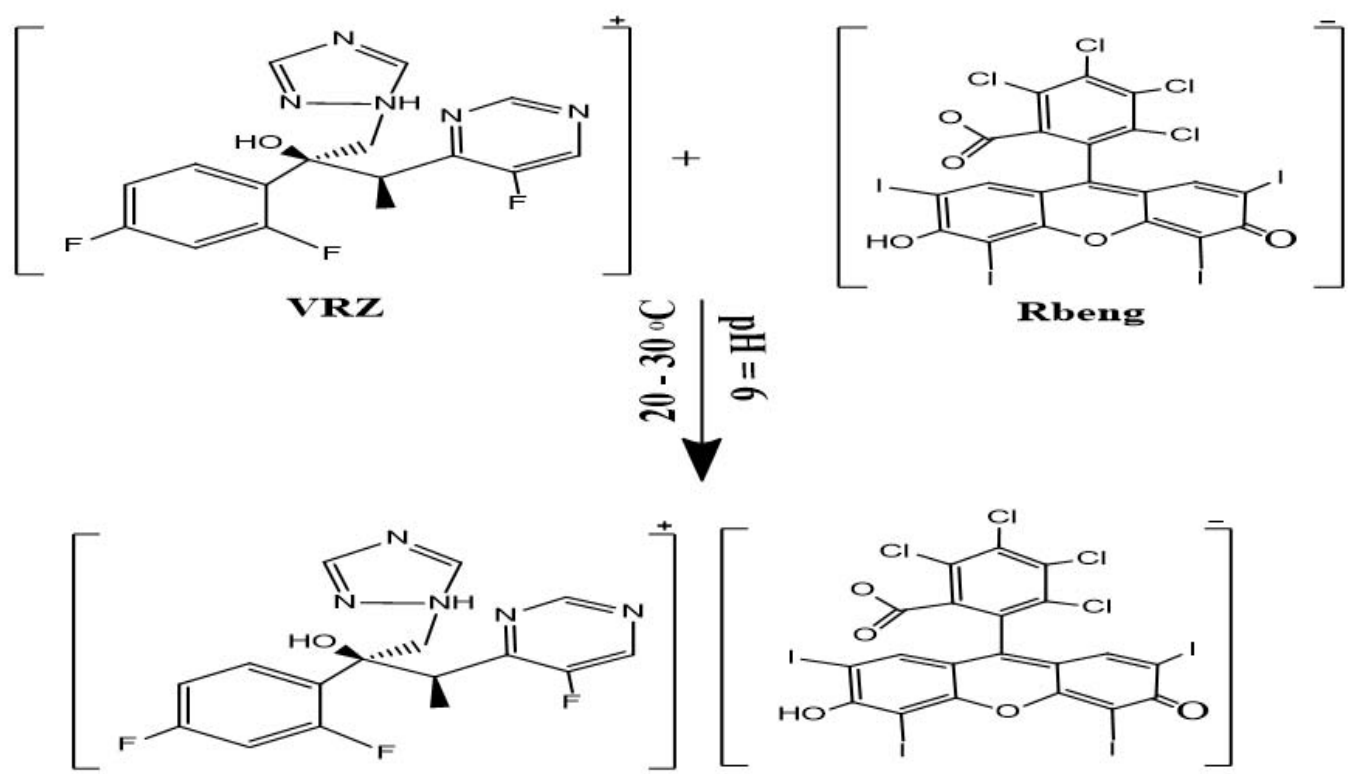

Scheme 1. Proposed scheme of the reaction between VRZ and Rbeng.

TABLE 1. Analytical parameters.

\begin{tabular}{|c|c|c|c|}
\hline $\begin{array}{l}\text { Drug } \\
\text { Parameters }\end{array}$ & FLZ & VRZ & BTZ \\
\hline Reagent & Rbeng & Rbeng & Rbeng \\
\hline$\lambda_{\text {max }}(\mathrm{nm})$ & 575 & 575 & 580 \\
\hline Temperature $(\mathrm{oC})$ & $20-30^{\circ} \mathrm{C}$ & $20-30^{\circ} \mathrm{C}$ & $20-30^{\circ} \mathrm{C}$ \\
\hline $\mathrm{pH}$ & 6.5 & 6.0 & 4 \\
\hline Beer's law $\left(\mathrm{Mg} \mathrm{mL}^{-1}\right)$ & $30.63-76.57$ & $34.93-97.81$ & $14.2-45.1$ \\
\hline $\operatorname{LOD}\left(\mathrm{Mg} \mathrm{mL}^{-1}\right)$ & 2.6 & 4.379 & 4.278 \\
\hline LOQ $\left(\mathrm{Mg} \mathrm{mL}^{-1}\right)$ & 8 & 13.27 & 12.96 \\
\hline $\mathrm{R}^{2}$ & 0.9981 & 0.9980 & 0.9989 \\
\hline Regression equation $(\mathrm{Y})^{*}$ & $y=0.0159 x-0.1109$ & $y=0.0132 x-0.0821$ & $y=0.0577 x-0.428$ \\
\hline $\begin{array}{l}\text { Molar absorptivity } \\
\left(\mathrm{L} \mathrm{mol}^{-1} \mathrm{~cm}^{-1}\right)\end{array}$ & $0.4883 \times 10^{4}$ & $0.4614 \times 10^{4}$ & $2.740 \times 10^{4}$ \\
\hline SD & $0.1210-0.4148$ & $0.4365-1.018$ & $0.0748-0.4362$ \\
\hline RSD \% & $0.1790-1.152$ & $0.5248-1.648$ & $0.3314-1.011$ \\
\hline $\begin{array}{l}\text { Sandell sensitivity } \\
\left(\mathrm{Mg} \mathrm{cm}^{-2}\right)\end{array}$ & 0.0627 & 0.0757 & 0.017331 \\
\hline Recovery \% & $98.00-101.9$ & $97.92-102.2$ & $98.20-101.3$ \\
\hline
\end{tabular}

Egypt. J. Chem. 60, No. 6 (2017) 
TABLE 2. Within - day precision of the determination of FLZ, VRZ, BTZ using Rbeng reagent.

\begin{tabular}{|c|c|c|c|c|c|}
\hline Drugs & $\begin{array}{l}\text { [Wt.] Taker } \\
\mu \mathrm{g} \mathrm{mL}^{-1}\end{array}$ & $\begin{array}{l}\text { [Wt.] Found } \\
\mu \mathrm{g} \mathrm{mL} \mathrm{L}^{-1}\end{array}$ & $\begin{array}{c}\text { Reoovery } \\
(\%)\end{array}$ & $\mathrm{SD}^{*}$ & $\begin{array}{c}\text { RSD }^{*} \\
(\%)\end{array}$ \\
\hline \multirow[t]{5}{*}{ FIZ } & 39.82 & 39.59 & 99.44 & 0.5306 & 1.339 \\
\hline & 45.94 & 45.75 & 99.58 & 0.4144 & 0.9087 \\
\hline & 52.07 & 51.33 & 98.59 & 0.3272 & 0.6374 \\
\hline & 58.19 & 57.63 & 99.04 & 0.5545 & 0.9600 \\
\hline & 64.32 & 63.78 & 99.17 & 0.5330 & 0.8348 \\
\hline \multirow[t]{5}{*}{ VRZ } & 52.40 & 52.10 & 99.43 & 0.7908 & 1.521 \\
\hline & 59.38 & 59.55 & 100.3 & 0.7302 & 1.226 \\
\hline & 73.36 & 73.38 & 100.0 & 0.6157 & 0.8374 \\
\hline & 80.34 & 80.66 & 100.4 & 0.6487 & 0.8038 \\
\hline & 87.33 & 87.63 & 100.4 & 0.6410 & 0.7321 \\
\hline \multirow[t]{5}{*}{ BTZ } & 21.37 & 21.68 & 101.5 & 0.3954 & 1.825 \\
\hline & 26.11 & 26.46 & 101.3 & 0.3177 & 1.200 \\
\hline & 30.86 & 30.98 & 100.4 & 0.4549 & 1.468 \\
\hline & 35.61 & 35.94 & 100.9 & 0.3560 & 0.9905 \\
\hline & 40.36 & 39.67 & 98.29 & 0.5085 & 1.283 \\
\hline
\end{tabular}

* Five replicate experiments at each concentration level within five hr.

TABLE 3. Between - day precision of the determination of FLZ, VRZ, BTZ using Rbeng reagent.

\begin{tabular}{|c|c|c|c|c|c|}
\hline Drugs & $\begin{array}{l}\text { [Wt.] Taken } \\
\text { mg mL. }\end{array}$ & $\begin{array}{l}\text { [WVt] Found } \\
\text { mg mL-i }\end{array}$ & $\begin{array}{c}\text { Recovery } \\
\text { (\%) }\end{array}$ & SD $^{2}$ & $\begin{array}{l}\text { RSD } \\
(\%)\end{array}$ \\
\hline \multirow[t]{5}{*}{ FIZ } & 39.82 & 38.89 & 97.67 & 0.3955 & 1.016 \\
\hline & 45.94 & 45.32 & 98.65 & 0.6270 & 1.382 \\
\hline & 52.07 & 51.64 & 99.17 & 0.4565 & 0.8820 \\
\hline & 58.19 & 57.63 & 99.04 & 0.4160 & 0.7213 \\
\hline & 64.32 & 64.29 & 99.59 & 0.5364 & 0.8330 \\
\hline \multirow[t]{5}{*}{ VRZ } & 52.40 & 51.93 & 99.10 & 0.5551 & 1.069 \\
\hline & 59.38 & 58.87 & 99.13 & 0.5073 & 0.8634 \\
\hline & 73.36 & 73.73 & 100.5 & 0.5117 & 0.6946 \\
\hline & 80.34 & 81.20 & 101.1 & 0.5238 & 0.6438 \\
\hline & 87.33 & 86.43 & 98.97 & 0.4562 & 0.5262 \\
\hline \multirow[t]{5}{*}{ BTZ } & 21.37 & 21.27 & 99.53 & 0.2614 & 1.229 \\
\hline & 26.11 & 26.15 & 100.2 & 0.2859 & 1.093 \\
\hline & 30.86 & 30.62 & 99.22 & 0.5130 & 1.675 \\
\hline & 35.61 & 36.03 & 101.2 & 0.4598 & 1.276 \\
\hline & 40.36 & 40.73 & 100.9 & 0.3841 & 0.9430 \\
\hline
\end{tabular}

*Five replicate experiments at each concentration level within five days 
TABLE 4. Application of the proposed method to the determination of the studied drugs in its pharmaceutical preparations.

\begin{tabular}{|c|c|c|c|}
\hline Sample & & Proposed method & Reported method \\
\hline FLZ & & & \\
\hline \multirow[t]{3}{*}{$\begin{array}{c}\text { Diflucan } \\
\text { (50 mg/cap.) }\end{array}$} & $\mathrm{X} \pm \mathrm{SD}^{\mathrm{a}}$ & $100.50 \pm 0.73$ & $99.75 \pm 1.2$ \\
\hline & $t$-Value ${ }^{b}$ & $1.2578(2.22) * *$ & \\
\hline & F-Value ${ }^{b}$ & $2.339(6.39) * *$ & \\
\hline \multicolumn{4}{|l|}{ VRZ } \\
\hline \multirow[t]{3}{*}{$\begin{array}{c}\text { Vfend } \\
(50 \mathrm{mg} / \mathrm{tab} .)\end{array}$} & $\mathrm{X} \pm \mathrm{SD}^{\mathrm{a}}$ & $100.0 \pm 0.67$ & $100.1 \pm 0.43$ \\
\hline & $t-$ Value ${ }^{b}$ & $0.2082(2.306) * *$ & \\
\hline & F-Value ${ }^{b}$ & $2.339(6.39) * *$ & \\
\hline \multicolumn{4}{|l|}{ BTZ } \\
\hline \multirow[t]{3}{*}{$\begin{array}{l}\text { Butoconazole } 2 \% \\
\text { cream }\end{array}$} & $\mathrm{X} \pm \mathrm{SD}^{\mathrm{a}}$ & $98.65 \pm 0.24$ & $98.21 \pm 0.52$ \\
\hline & t-Value ${ }^{b}$ & $1.6853(2.447) * *$ & \\
\hline & F-Value $^{\mathrm{b}}$ & $0.2089(6.94) * *$ & \\
\hline
\end{tabular}

${ }^{a}$ Mean values for five replicates, ${ }^{* *}$ the values between brackets are the ${ }^{\mathrm{b}}$ tabulated $\mathrm{F}$ - and $\mathrm{t}$-values at $\mathrm{P}=0.05$.

\section{Conclusion}

The data given above revealed that the proposed method is simple, accurate and sensitive with good precision and accuracy. Also, the reagent utilized in the proposed method is cheaper, readily available and the procedure does not involve any critical reaction conditions or tedious sample preparation. Thus, this proposed spectrophotometric method can be successfully applied for the determination of FLZ, VRZ and BTZ in the pure form and in pharmaceutical preparations.

\section{References}

1. Walsh T.J., Hiemenz J.W. and Anaissie E., Recent progress and current problems in treatment of invasive fungal infections in neutropenic patients. Infect Dis Clin North Am. 10, 365-400 (1996).

2. Saravana K. N. and Purnima S., Candida albicans Lanosterol $14 \alpha$-demethylase: Structural insights into its molecular mechanisms and mode of inhibition by azole antifungals. Int.J.Res.pharma. sci. 2(4), 498-511 (2011).

3. Arnold T.M., Dotson E., Sarosi G.A. and Hage C.A., Traditional and emerging antifungal therapies. Proc Am Thorac Soc. 7, 222-228 (2010).

4. Ghannoum M. A., Future of ant mycotic therapy. Der matol. Ther. 3, 104-111 (1997).

5. Koltin Y. and Hitchcock C. A., Progress in the search for new triazole antifungal agents. Curr. Opin. Chem. Biol. 1, 176-182 (1997).

6. Nafsika H. G. and Thomas J. W., Antifungal agents: Chemotherapeutic targets and immunologic strategies. Antimicrob. Agents che-mother. 40, 279291 (1996).

7. White T. C., Marr K. A. and Bowden R. A., Clinical, cellular, and molecular factors that contribute to antifungal drug resistance. Clin. Microbiol. Rev. 11, 382-402 (1998).

8. Chunquan S., Wannian Z., Haitao J. i., Min Z., Yunlong S., Hui X., Jie Z., Zhenyuan M., Qingfen J., Jianzhong Y., Youjun Z., Ju Z. and Jiaguo L., Structure-based optimization of azole antifungal

Egypt. J. Chem. 60, No. 6 (2017) 
agents by CoMFA, CoMSIA, and molecular docking. J. Med. Chem. 49, 2512-2525 (2006).

9. Daniel J. S., Christopher A. H. and Carol M. S., Current and emerging azole antifungal agents. CMR. 12, 40-79 (1999).

10. David A. W. and Thomas L. L., Foye's Prin- ciples of Medicinal Chemistry. 5th Edition. 891- 901 (2007).

11. JALALI, Fahimeh, RAJABI, Mohammad, J., Extractive spectrophotometric determination of fluconazoleby ion-pair complex formation with bromocresol green. Chin.J.Chem. 25, 1300-1303( 2007).

12. Paula B., Marina V. A. and Huander F. A., Alessandro C. Pasqualotto and Rafael Linden. Ultra-performance liquid chromatographic method for measurement of voriconazole in human plasma and oral fluid, J. Braz. Chem. Soc. 23, 148-155 (2012).

13. Walker K. A., Braemer A. C., Hitt S., et al., 1-[4-(4-Chlorophenyl)-2-(2,6-dichlorophenylthio)n-butyl]-1H-imidazole nitrate, a new potent antifungal agent. $J$ Med Chem. 21(8), 840-843 (1978).

14. Tatum D.M. and Eggleston M., Butoconazole nitrate, Infect Cont Hosp Epidemiol, 9(3), 122-124 (1988).

15. Droegemueller W., Adamson D. G. and Brown D., Three-day treatment with butoconazole nitrate for vulvovaginal candidiasis. Obstet Gyn. 64(4), 530534(1984).

16. Jacobson J.B., Hajman A.J. and Wiese J., A new vaginalantifungal agent-butoconazole nitrate. Acta Obstet Gyn Scan. 64(3), 241-244 (1985).

17. Bradbeer C. S., Mayhew S. R. and Barlow D., Butoconazole and miconazole in treating vaginal candidiasis. Genitourin Med. 61(4), 270-272(1985).

18. Brown Jr. D., Henzl M. R. and LePage M.E., Butoconazole vaginal cream in the treatment of vulvovaginal candidiasis comparison with miconazole nitrate and placebo. J Reprod Med. 31(11), 1045 (1986).

19. Seidman L. S. and Skokos C. K., An evaluation of Butoconazole nitrate $2 \%$ Site Release ${ }^{\circledR}$ vaginal cream (Gynazole-1®) compared to fluconazole $150 \mathrm{mg}$ tablets (Diflucan ${ }^{\circledR}$ ) in the time to relief of symptoms in patients with vulvovaginal candidiasis. Infect Dis Obstet Gynecol. 13(4),197-206 (2005).
20. Hajman A. J. and Vulvovaginal C., Comparison of 3-day treatment with $2 \%$ butoconazole nitrate cream and 6-day treatment with 1\% clotrimazole cream. J Int Med Res. 16 (5), 367 (1988).

21. Pothana S., Nalini S. and Sadanandam M., Development and validation of a stabilityindicating Rp-Uplc method for the determination of fluconazole in bulk drug and in pharmaceutical dosage forms. IJPBS. 4,128-140 (2014).

22. Hayam M. L., Abdel-Aziz B. A. and Hany H. M., Stability-indicating high performance liquid chromatographic determination of fluconazole in the presence of its oxidative degradation product kinetic and stress study. J. Liq. Chrom. \& R. Techn. 36(10), 1013-1029 ( 2013).

23. Josilene C. R. C., Camila R., Hérida R. N. S. and Cristina D. V., Performance characteristics of high performance liquid chromatography, first order derivative UV spectrophotometry and bioassay for fluconazole determination in capsules. Quim. Nova. 35(3), 530-534 (2012).

24. Sahu S., Narayan U. L., Garnaik B. and Patro S. K., Bio-analytical method development and validation of voriconazole using LC-MS/MS. RJPBCS. 5(3), 1783-1793 (2014).

25. Eswara Rao B., Vaikuntarao L. and Rathnakar R. K., Method development validation and degradation studies of voriconazoledrug by RP-HPLC method. IJCPS. 2(9), 1149-1154 (2014).

26. Reddy C.M.B., Spectrophotometric estimation of Fluconazole in pure drug and pharmaceutical formulation, IJSER.,3(9), 1-7(2012).

27. Bodavula S.S.R., Eligeti S. K. and Ganna K. K., Methods development of fluconazole tablets (400 $\mathrm{Mg}$ ), The Pharma Innovation, 1(7),113-115 (2012).

28. Srinu Babu G, Raju Ch A I; UV-spectrophotometric determination of voriconazole in bulk and its formulation, Asian Journal of Chemistry, 19(2),1625-1627 (2007).

29. Deepan T., Alekhya V., Senniappan P. and Dhanaraju M. D.; Method Development And Validation For The Estimation Of Voricanazole By Uv Spectroscopy, Inter. J. Chem. Pharm. Sci., 5 (2),164-167 (2014).

30. Raval K. and Kevin M., Development of new colorimetric method and validation for determination of voriconazolein bulk and marketed formulation, , IJRPC, 3(3), 712-722 (2013).

31. Shaik R., Sreem D. and Aravind G., Development 
and validation of new analytical method for voriconazole for injection by using $\mathrm{UV}$ spectrophotometer, Int. J.A. PS. BMS , 1(3), 240247 (2012).

32. Knoth H., Petry T. and Gärtner P., Differential pulse polarographic investigation of the antifungal drugs itraconazole, ketoconazole, fluconazole and Voriconazole using a dropping mercury electrode, Pharmazie, 67, 987-990 (2012).

33. Nawal A. Alarfaj and Maha, F. E., Electrochemical Sensors For Direct Potentiometric Determination Of Voriconazole In Pharmaceutical Dosage Forms And Biological Fluids, International Journal of Physical Sciences, 7(9),1403-1411(2012).

34. Britton H. T. S., Hydrogen Ions, 4th edition, Chapman and Hall, London, (1952).
35.Vosburgh W. C. and Cooper G. R, complex ions- ithe identification of complex ions in solution by spectrophotometric measurements, J. Am. Chem. Soc, 63(2), 437-442 (1941).

36. Yoe J.H. and Jones A.L., Colorimetric Determination of Fe with Disodium 1, 2- Dihydroxybenzene-3, 5Disulfonate, Ind Eng Chem Anal Ed, 16 (2), 111115 (1944).

37. Miller J., Miller J. and Saeed Ahmed; Statistics and Chemometric for Analytical Chemistry $6^{\text {th }}$ edn, (2010).

(Received 5/7/2017; accepted 7/11/2017)

\title{
التقدير الطيفي لأدوية القلوكونازول ،القوريكونازول والبيوتوكونازول نيترات عن طريق

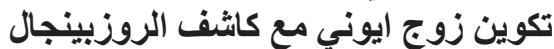 \\ محمد عبد الجواد زايد1، منال الثال2ّ و مروه عبد العظيم 2

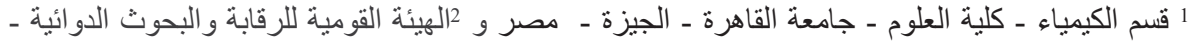

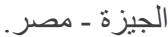

\begin{abstract}
تم دراسة تفاعلات كاثف الروز بنجال مع الأدويه الثناثة المضادة للفطريات الفلوكونازول، الفوريكونازول

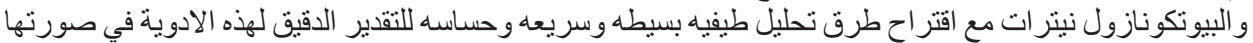

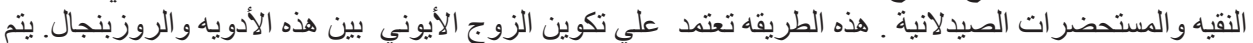

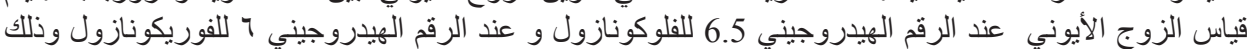

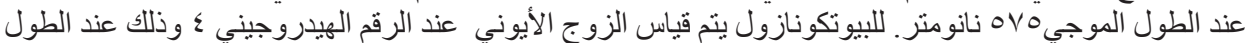

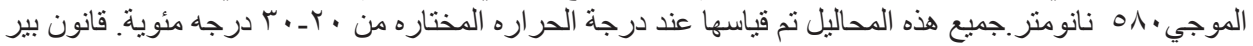

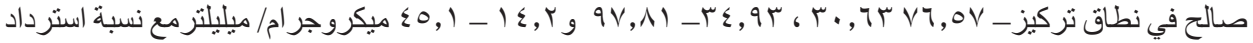

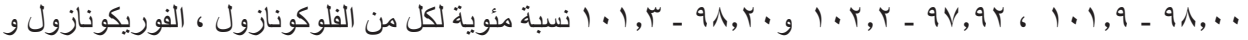

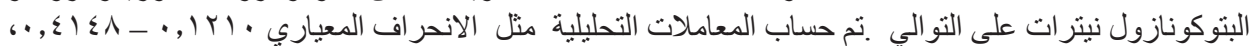

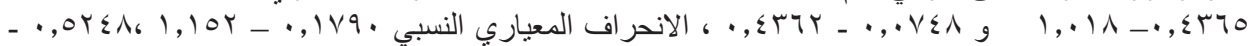

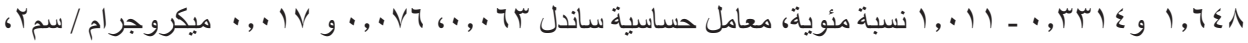

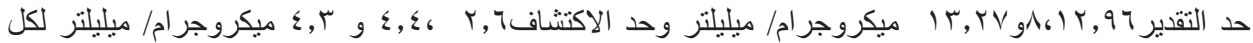

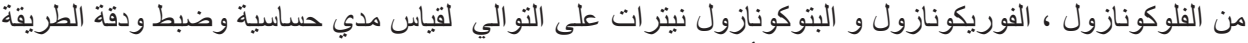

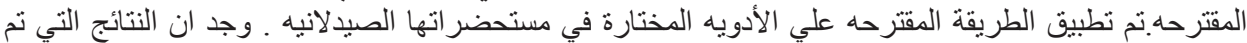

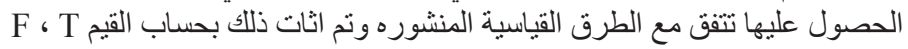

